\title{
SACRAL DIFFUSE LARGE B-CELL LYMPHOMA PRESENTED AS CAUDA EQUINA SYNDROME. Case report
} and systemic review.

\author{
Humberto Foyaca-Sibat ${ }^{1}$ \\ ${ }^{1}$ Walter Sisulu University
}

June 18, 2021

\begin{abstract}
ABSTRACT: Background: Cauda equina syndrome secondary (CES) to primary sacral diffuse large B cell lymphoma (DLBCL) is an uncommon condition, and few cases have been reported in the medical literature. After an extensive literature review related to these topics, we did not find a reported case like our patient.
\end{abstract}

\section{Hosted file}

final SACRAL B-CELL LYMPHOMA PRESENTED AS CAUDA EQUINA SYNDROME.doc available at https: //authorea.com/users/420445/articles/526790-sacral-diffuse-large-b-cell-lymphomapresented-as-cauda-equina-syndrome-case-report-and-systemic-review

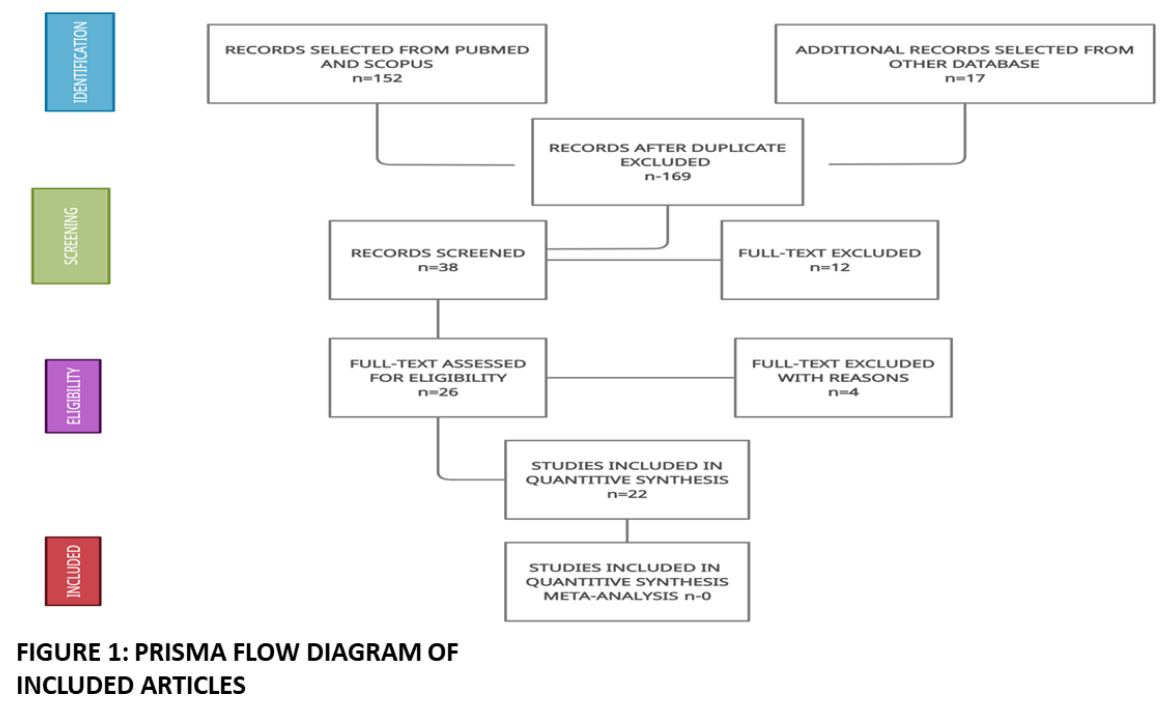


TABLE 1

AGE GROUP(YRS.)

\& REFERENCES.

1- $9-n=1$ [32]

TYPE OF TUMOUR

TREATMENT

OUTCOME

10-19-n=1 [33]

NOS- $n=1$

SURGERY

GOOD

20-29- $n=4[34,35]$

HD-n=2, DLBCL-n=1, NR-n=1

$\mathrm{R}-\mathrm{CHOP}-\mathrm{n}=1$

GOOD

$30-39-n=3$

LCL-n1, DLBCL-n=2

R-CHOP-n=1

GOOD

[26, 36-38]

40-49- $n=37$

NOS-n=35, DBLCL-n=2

$N R-n=1$ SURGERY- $n=2$

GOOD

[39-41]

50-59- $n=4$

NOS-n=1, DBLCL-n=3

NR-n=35

NR-n-35

[29,42-45]

60-69-n=4[46]

70-79-n=1[47]

DBLCL-n=2

$N R-n=1$

$N R-n=2$

$80-89-n=2[31,48]$

DBLCL-n=1

R-CHOP-n=2

$\mathrm{R}-\mathrm{CHOP}-\mathrm{n}=2$

R-CHOP- $n=1$

Total $n=54 / 100 \%$

DBLCL-63.15\%

R-CHOP-n $=1$

GOOD

R-CHOP-19.04\%

GOOD- $88.88 \%$
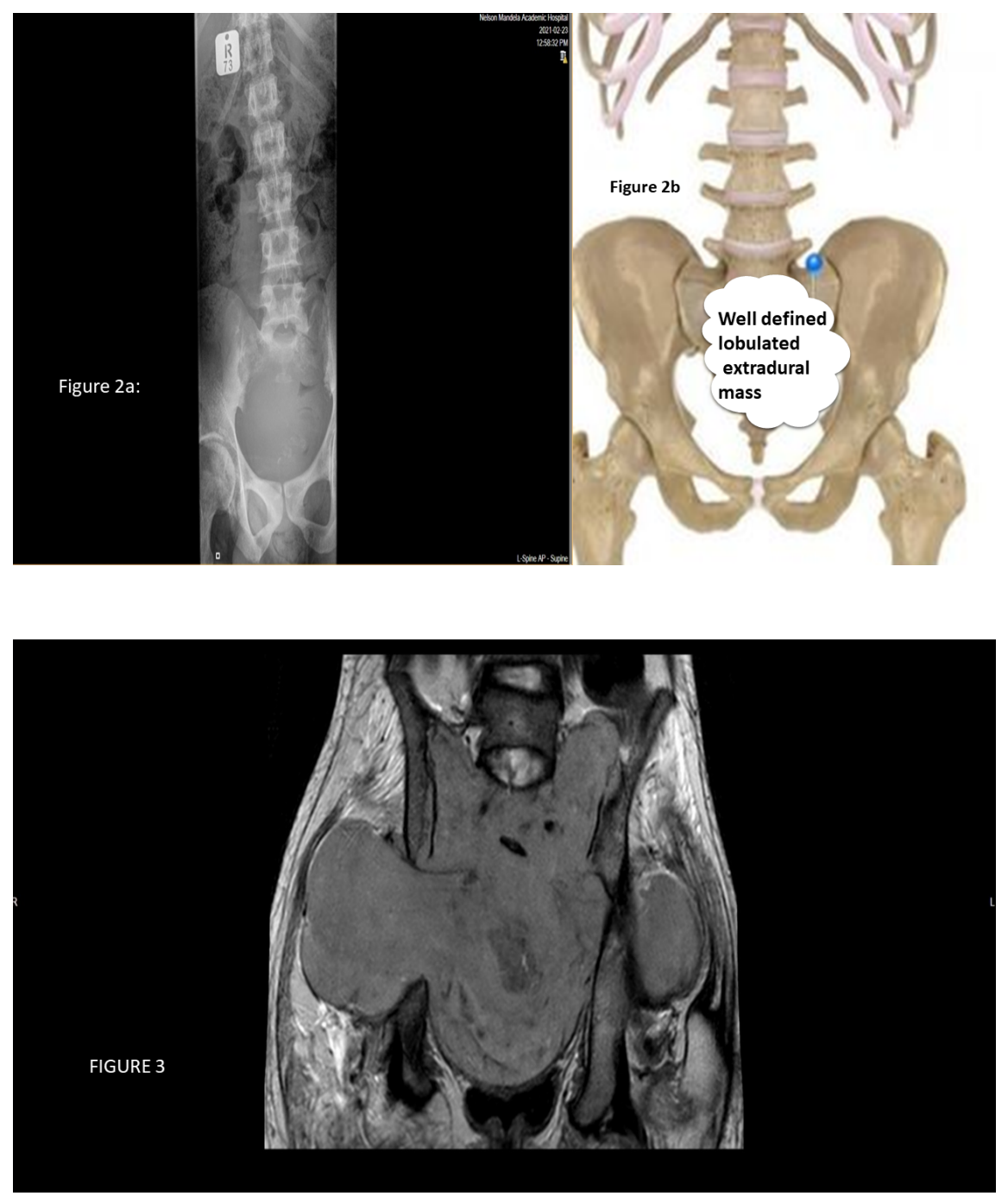

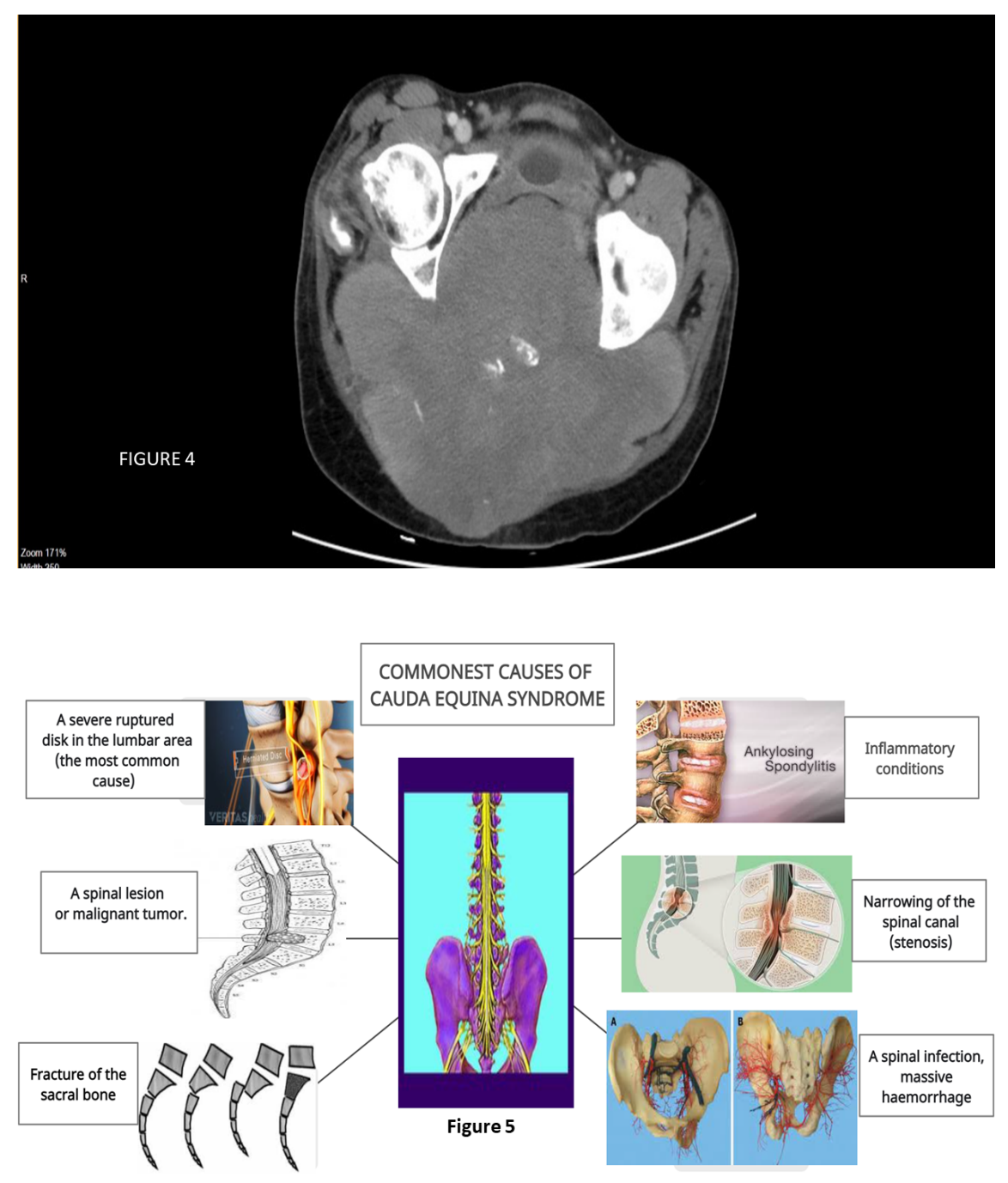